\title{
A noção de estrutura e os registros de informação dos sistemas documentários ${ }^{1}$
}

\author{
The notion of structure and the information records of the \\ documentary systems
}

Cristina Dotta ORTEGA²

Marilda Lopes Ginez de LARA ${ }^{3}$

\begin{abstract}
RESUMO
Partindo da constatação de que os princípios e os métodos para construção e gestão dos sistemas documentários são dispersos e carecem de sistematização, este artigo levanta a hipótese de que a noção de estrutura, ao pressupor relações mútuas entre os seus elementos, confere maior organicidade aos sistemas e garante maior qualidade e consistência na recuperação da informação frente às questões dos usuários. Desse modo, objetiva explorar fundamentos, a partir da noção de estrutura, dos registros de informação e dos sistemas documentários. Para tanto, são apresentados conceitos básicos e questões relativas aos sistemas documentários e aos registros de informação. Posteriormente, elenca aportes teóricos sobre a noção de estrutura, tratados por Benveniste, Ferrater Mora, Hjelmslev, Lévi-Strauss, Lopes, Peñalver Simó, Saussure, além de Ducrot, Fávero e Koch, para então tratar das apropriações já realizadas pela Documentação por Paul Otlet, García Gutiérrez e Moreiro González. Conclui-se que a noção de estrutura adotada para tornar explícita uma hipótese de sistematização do real, a partir de um modelo, assegura maior organicidade aos sistemas, bem como confere referência pedagógica ao fazer documentário.
\end{abstract}

Palavras-chave: Bases de dados. Estrutura. Registros de informação. Sistemas documentários.

\begin{abstract}
A B S T R A C T
Assuming as a starting point the acknowledge that the principles and methods used to build and manage the documentary systems are disperse and lack systematization, this study hypothesizes that the notion of structure, when assuming mutual relationships among its elements, promotes more organical systems and assures better quality and consistency in the retrieval of information concerning users' matters. Accordingly, it aims to explore the fundamentals about the records of information and documentary systems, starting from the notion of structure. In order to achieve that, it presents basic concepts and relative matters to documentary systems and information records. Next to this, it lists the theoretical subsides over the notion of structure, studied by Benveniste, Ferrater

1 Trabalho apresentado no X Encontro Nacional de Pesquisa da ANCIB - ENANCIB 2009, realizado em João Pessoa (PB), Brasil.

2 Universidade Federal de Minas Gerais, Escola de Ciência da Informação. Av. Pres. Antônio Carlos, 6627, 31270-901, Pampulha, Belo Horizonte, MG, Brasil. Correspondência para/Correspondence to: C.D. ORTEGA. E-mail: <ortega@eci.ufmg.br>.

3 Universidade de São Paulo, Escola de Comunicações e Artes, Departamento de Biblioteconomia e Documentação. São Paulo, SP, Brasil.

Recebido em 21/1/2009 e aceito para publicação em 15/4/2010.
\end{abstract}

TransInformação, Campinas, 22(1):7-17, jan./abr., 2010 
Mora, Lévi-Strauss, Lopes, Peñalver Simó, Saussure, apart from Ducrot, Favero and Koch. Appropriations that have already been done by Paul Otlet, García Gutiérrez and Moreiro González. In Documentation come as a further topic. It concludes that the adopted notion of structure to make explicit a hypothesis of real systematization achieves more organical systems, as well as it grants pedagogical reference to the documentary tasks.

Keywords: Data bases. Structure. Information records. Documentary systems.

\section{NTRODUÇÃ O}

Enquanto sistemas documentários, as bases de dados são compostas por registros e cada registro é composto por campos. Como o registro é a unidade principal de trabalho de uma base de dados, decorre que seja a unidade de interpretação do sistema.

Os registros de informação dos sistemas documentários devem ser produzidos a partir de representações de entidades ${ }^{4}$ e de questões de busca (previstas) dos usuários. Para sua funcionalidade, é esperado que os registros apresentem características que garantam aderência entre essas representações e as questões de busca efetivamente realizadas pelos usuários. Os princípios que fundamentam essa aderência na forma física de um registro de informação de um sistema são as questões essenciais deste trabalho.

Esses princípios devem sustentar a construção e gestão dos sistemas documentários, os quais são, no entanto, dispersos e pouco sistematizados na literatura. Atualmente, princípios são demandados para subsidiar os debates em curso sobre Catalogação, contribuindo para a compreensão de instrumentos documentários como modelos de referência, ainda que sejam produtos de contingências históricas (políticas, econômicas e tecnológicas). É desejável também subsidiar a construção e o uso de instrumentos em processo de desenvolvimento pela Ciência da Computação, como as ontologias.

Neste artigo trabalha-se com a hipótese de que a noção de estrutura, ao pressupor relações mútuas entre os seus elementos, confere maior organicidade aos sistemas documentários e garante maior qualidade e consistência na recuperação da informação frente às questões dos usuários. Desse modo, objetiva-se explorar fundamentos, a partir da noção de estrutura, dos registros de informação e dos sistemas que compõem.

Para tanto são apresentados conceitos básicos e questões relativas aos sistemas documentários e aos registros de informação e à sua produção e gestão. Posteriormente, elenca-se alguns aportes teóricos sobre a noção de estrutura, tratados por Lévi-Strauss (1958, citado por Peñalver Simó, 1972), Saussure (1969), Hielmslev (1971, citado por Lopes, 1987), Peñalver Simó (1972), Lopes (1987), Benveniste (1991), Ferrater Mora (1998), além de Ducrot (1968, citado por Paveau; Sarfati, 2006) e Fávero e Koch (1998), para então tratar das apropriações já realizadas pela Documentação por Paul Otlet (1934), García Gutiérrez (1984) e Moreiro González (2004).

\section{OS SISTEMAS DOCUMENTÁRIOS E OS REGISTROS DE INFORMAÇÃO}

\section{Os sistemas documentários}

Para Meyriat (1981), o sistema documentário é entendido como um conjunto de elementos ligados entre si, de modo a serem interdependentes e orientados, tendo em vista atender um objetivo: obter informação.

Os sistemas documentários são compostos por unidades potencialmente informacionais selecionadas e organizadas, de tal modo que a seleção realizada e a relação estabelecida entre essas unidades deflagram a hipótese de organização adotada para o sistema. Esses sistemas caracterizam-se por suas unidades informacionais constituintes e pelos serviços que

\footnotetext{
4 Entidade faz parte da terminologia da Ciência da Computação. No contexto dos tradicionais sistemas de informação bibliográfica, as entidades podem ser documentos, grupos de documentos e/ou partes de documentos, que compõem uma coleção.
} 
promovem acesso a essas informações e seu uso efetivo. Aspectos relativos à coleção e a suas referências definem os sistemas documentários e permitem demonstrar sua diversidade.

As referências, produzidas no âmbito dos sistemas documentários, são as unidades concretas a que chamamos de registros de informação. Os registros são representações documentárias, no sentido de produto, ou resultado da representação documentária, no sentido de processo. Apresentam elementos simbólicos aqui denominados de informações documentárias - os quais possuem competência para informar, pois operam com a significação. Informação documentária é aquela apreendida, registrada e armazenada em um sistema de informação (documentária) de forma a ser passível de recuperação e uso para os mais diversos fins demandados pela sociedade. Dito de outro modo, os registros de informação são instâncias físicas, cuja instância simbólica são as informações documentárias. Por esse motivo, os sistemas aqui referidos são denominados de sistemas de informação documentária, ou simplesmente, sistemas documentários.

Com base em Moreiro González (1998), entende-se que o sistema documentário opera como uma intervenção artificial na produção e uso do conhecimento, a qual permite aos usuários acesso qualificado à informação. Assim a intervenção realizada pelo sistema refere-se a ações voltadas à gestão do fluxo da informação (a instância simbólica) e à gestão do fluxo dos documentos (a instância física que, em geral, inclui os registros de informação do sistema e os documentos referenciados nesses registros).

Desse modo, os sistemas documentários viabilizam a organização da informação por meio da determinação de campos e do seu preenchimento, formando unidades representativas de entidades e de questões (previstas) de usuários, e promovem a busca da informação por meio da formulação de questões que são equiparadas a tais unidades (Abadal; Codina, 2005).

Recolocando a afirmação de Tálamo (1997), o sistema é simultaneamente um modo de organização e uma forma de comunicação da informação. Mais especificamente, a comunicação documentária é o "processo que envolve a codificação e a decodificação de conteúdos informacionais, ou seja, o tratamento e a recuperação da informação" (Lara, 1993, p.4). Com base nessa autora, Cohen (1995) parte da proposição de que os sistemas documentários constituem-se como sistemas de comunicação, nos quais há emissão e recepção de mensagens, isto é, ocorre um processo comunicacional denominado comunicação documentária, destinado a - por meio do produto documentário - tornar o usuário informado. $\bigcirc$ usuário é o ator que dispara uma situação de comunicação, pois é o ato da recepção que determina o estabelecimento ou não de uma comunicação. Segundo ela, para que a comunicação documentária ocorra, é necessário que a informação documentária - produto que é transmitido nesse processo - seja portadora de um significado tal que o usuário possa ser capaz de processá-la mentalmente, a fim de obter a informação desejada. A comunicação documentária é, então, um processo que exige, de um lado, a informação documentária e, de outro, o usuário que se apropria dessa informação. Os sistemas documentários lidam com atos de comunicação materialmente explícitos, isto é, o documento, sua representação, a pergunta do usuário, a ação comunicativa do profissional de informação etc.

\section{Os processos de construção dos registros de informação}

Os registros de informação dos sistemas documentários são produtos da análise e representação de documentos, embora nem sempre um registro corresponda a apenas um documento ou a um documento como um todo.

Em especial quanto ao trato da informação bibliográfica, são adotados os termos Representação Descritiva e Representação Temática para indicar as etapas distintas e complementares necessárias à construção dos registros de informação. A Representação Descritiva ocupa-se dos registros de informação no que tange aos aspectos da descrição formal dos documentos, o que inclui os processos de descrição física e dos elementos de sua identificação; a atividade de representação descritiva é também chamada de catalogação - em especial entre a comunidade de bibliotecas - e de descrição bibliográfica - na comunidade dos serviços de informação científica. A Representação Temática opera na atribuição de assuntos aos 
documentos, a partir dos processos de: classificação bibliográfica, indexação e elaboração de resumos. A classificação bibliográfica tem sido realizada por meio de representação documentária mais genérica que a da indexação, com o objetivo de realizar a ordenação de documentos para acesso ${ }^{5}$; na indexação são elaborados pontos de acesso que remetem ao registro, o qual indica em geral um documento; e a elaboração de resumos apresenta como produto um texto síntese que possui uma relação de contiguidade e semelhança com o original e que deve servir como meio de decisão para a busca ou não do documento pelo usuário.

É provável que os termos Representação Descritiva e Representação Temática tenham sido adotados com o objetivo de ampliar o conceito de Catalogação, já que tal conceito corresponde essencialmente à elaboração de catálogos de biblioteca. A Catalogação, incluindo a Catalogação Descritiva e a Catalogação de Assunto, responde pela construção global do sistema documentário, nesse caso, o catálogo (Garrido Arilla, 1996). Supõe-se que, devido à busca por especialização, o desenvolvimento teórico e metodológico da Representação Descritiva e da Representação Temática foi realizado de modo separado, conduzindo a dificuldades conceituais na articulação entre os dois processos.

A Representação Temática consolidou-se principalmente em virtude do desenvolvimento dos fundamentos das linguagens documentárias, que objetivou promover maior estruturação à atividade empírica de atribuição de termos indexadores. Contudo, foram realizados investimentos diferenciados: um, relativo aos fundamentos das linguagens documentárias e à sua construção, e outro relativo aos métodos de indexação. A linguagem documentária configura-se como estrutura que permite preencher de modo qualificado os campos de conteúdo temático do registro, mas não fornece os parâmetros necessários à elaboração desses campos. Para que decisões relativas aos campos sejam tomadas, a linguagem documentária precisa ser desenvolvida em conjunto com a políitica de indexação, a qual, por sua vez, deve fazer parte da política geral de tratamento da informação, o que nos remete às questões do sistema como um todo. Em termos procedimentais, pode-se dizer que há aspectos estruturais do registro relativos aos campos temáticos que precisam ser pensados em suas características próprias e de forma articulada aos outros campos que vão compor o registro.

A Representação Descritiva tende a ser explicada pelo uso de instrumentos documentários amplamente disseminados, como o Anglo-American Cataloguing Rules (AACR2) e o Machine Readable Cataloging (MARC), menos que por seus princípios. Quanto a essa atividade, princípios de Catalogação receberam primeira sistematização na metade do século XIX. As regras para as atividades de catalogação, e o modo como são muitas vezes utilizadas, distanciaram-se dos princípios que as geraram, ainda que, subjacente a tais regras, haja relevante acúmulo metodológico. A questão é a de que os instrumentos citados nem sempre são utilizados como modelos de referência para a operação dos sistemas, mas apenas como padrões de tratamento da informação, legitimados internacionalmente e economicamente viáveis (Ortega, 2009a).

As inconsistências citadas são observáveis nas práticas de construção e gestão de sistemas documentários, bem como no ensino. Nesse contexto, são identificadas várias comunidades de profissionais e de pesquisadores e professores, como a comunidade de bibliotecas, de serviços de informação científica, de produção de metadados e de tecnologia da informação e da comunicação. Esses grupos não são constituídos de modo exclusivo e se mantêm em atividades que são simultaneamente de interação e de conflito.

É possível afirmar que a relação entre Representação Descritiva e Representação Temática está mal construída, ou seja, há uma desarticulação entre elas que apresenta implicações para a área. Alguns fatos demonstram isso: a pesquisa que aborda a primeira conhece pouco a segunda e vice-versa; a Representação Descritiva desenvolveu-se menos que a Representação Temática em termos conceituais e sua longa história de práticas profissionais e de elaboração e uso de normas não permitiu ainda superar tal diferença; e, quanto às teorias e metodologias da Representação Descritiva e da Representação Temática que sustentam e integram a ideia de sistema e de registro de informação há lacunas, mas elas não são suficientemente consideradas e enfrentadas.

\footnotetext{
5 A classificação bibliográfica realizada com uso da Classificação Decimal Universal (CDU), por exemplo, permite a construção de notações bastante específicas. Embora a concepção desse instrumento não tivesse levado em conta a ordenação de documentos, é em geral utilizado desse modo hoje.
}

TransInformação, Campinas, 22(1):7-17, jan./abr., 2010 
O conceito de normalização documentária é pertinente ao tema tratado, mas perde a dimensão que the compete frente às atividades de catalogação e de normalização de trabalhos científicos, quando realizadas de modo mecânico. Por esse motivo, interessa a abordagem proposta por García Gutiérrez (1984) ao afirmar que, em geral, é necessário normalizar todas aquelas atividades movidas por impulsos sistemáticos, regulares e que necessitam de um método como único meio de alcançar resultados. Entende que seja óbvio que a normalização de códigos seja fator imprescindível e condicionante para a comunicação entre os homens. Para ele, a normalização documentária envolve a organização racional dos conhecimentos e de seus suportes, bem como o tratamento e dinamização do conjunto acumulado, trabalho que poderia ser parcelado nas diferentes áreas do esquema tradicional, transcrito por Chaumier em 1974 (García Gutiérrez, 1984), a saber: seleção, tratamento e difusão documentárias. A normalização documentária implica, portanto, a regulação das distintas fases do processo pelas quais passam os documentos. Os documentos, por sua vez, são a medula nuclear de todas as técnicas que serão tratadas, e afloram, em sua denominação mais tradicional, como a causa (documento original), o efeito (documento referencial), e o fim (informação científica) do trabalho realizado em centros e sistemas documentários.

Pode-se inferir, com base nas ideias do autor, que transformar objetos ou dados em documentos implica esforço de normalização. Sendo o documento de que trata a Ciência da Informação aquele produzido com fins de promover o acesso à informação a partir de sistemas documentários, então a Representação Descritiva e a Representação Temática são esforços de normalização cujo produto é o documento referencial ou secundário. Dentre os documentos secundários, trata-se aqui dos registros de informação dos sistemas de bases de dados.

\section{A NOÇÃO DE ESTRUTURA E OS REGISTROS DE INFORMAÇÃO DOS SISTEMAS DOCUMENTÁRIOS}

\section{A noção de estrutura nas ciências}

Estrutura é um termo comum a várias ciências. Quando se fala em estrutura na Filosofia, persegue-se a tentativa de buscar propriedades comuns em estruturas concretas. Entende-se por estrutura um conjunto de elementos relacionados entre si segundo determinadas regras, ou um conjunto ou grupo de elementos funcionalmente correlacionados. O traço mais importante da noção de estrutura é que o conjunto ou grupo não é mera soma, mas integração, uma vez que seus membros são necessariamente interligados de modo interdependente, sendo definidos uns relativamente aos outros. Estrutura também pode ser entendida como um conjunto ou grupo de sistemas. É um modo de ser dos sistemas, de tal forma que eles funcionam em virtude da estrutura que têm (Ferrater Mora, 1998).

No sentido tradicional, estrutura (Peñalver Simó, 1972, p.71) evoca a ideia de solidariedade, relação entre elementos e entre as partes de um todo. Como sinônimo de esqueleto, ou armação, a noção se enriquece agregando-se a ela a ideia de "organização fundamental, privilegiada do objeto considerado, que permite distinguir o essencial do acessório: mas trata-se de uma organização observável, cujas relações estão ao mesmo nível [...]". Mesmo assim, ela induz à ideia de comparação por semelhanças, da qual se caminha para a possibilidade de reproduzi-la abstratamente.

A noção de estrutura, porém, não se confunde com mera organização quando se trata da análise proposta pelo estruturalismo. No início do século XX, a noção foi utilizada por Saussure na Linguística por meio do termo sistema. O emprego do termo estrutura, pela primeira vez em Linguística, foi feito em Praga, no $1^{\circ}$ Congresso dos Filólogos Eslavos, em 1928, pelos russos Jakobson, Karcevisky e Trubetzkoi (Lopes, 1987).

A noção de estrutura liga-se à de relação no interior de um sistema (Benveniste, 1991). Para Peñalver Simó (1972), a diferença entre a visão tradicional de estrutura e a proposta no âmbito da Linguística reside no fato de ela não ser nem uma parte privilegiada de um conjunto - não é pois sinônima de esqueleto ou armação -, nem se situar no mesmo nível de outras entidades relacionais observáveis no sistema. Do que se deduz que: "1) a configuração contida na noção de estrutura não é observável empiricamente [...] Como disse Lévi-Strauss, em 1958 (Peñalver Simó, 1972, p.73) "a noção de estrutura social não corresponde à realidade empírica, mas a modelos construídos a partir dela"; 2) os termos da configuração estrutural formam parte das organizações visíveis do objeto sistematizado. 
Mas a estrutura está construída com relações destes mesmos termos situadas em um nível 'inconsciente' $[\ldots]^{\prime \prime}$.

Hjelmslev, em 1971, definiu melhor o conceito quando advertiu que estrutura é um modelo, uma construção mental que serve de hipótese de trabalho. Ao propor o escopo da Linguística Estrutural, Hjelmslev postulou a possibilidade de descrever a linguagem como sendo essencialmente uma entidade autônoma de dependências internas. "A análise dessa entidade permite constantemente isolar partes que se condicionam reciprocamente, cada uma delas dependendo de algumas outras, sendo inconcebível e indefinível sem essas outras partes" (Lopes, 1987, p.39).

As noções estruturais formuladas pela Linguística foram em seguida utilizadas por outras áreas das ciências humanas e sociais em função da homologia existente entre o linguístico e o social e cultural. Nelas, a estrutura consiste num sistema de relações que é fruto de operações de observação e de seleção, como uma primeira operação de raciocínio científico. A rede de relações que compõe uma estrutura não é aparente, mas supõe princípio epistemológico anterior que é o da sistematicidade do real, visto que só o sistemático é inteligível cientificamente.

A noção de sistema de Saussure, que deu origem à de estrutura, foi sendo submetida, ao longo do tempo, à crítica e à revisão. Ao incluir o sujeito, as teorias da linguagem passam a observar o caráter dialógico da linguagem e a recepção. Baktin questionou a definição abstrata e monolítica do sistema da língua, propondo substituí-la por uma concepção dialógica da linguagem, segundo a qual as expressões concretas dos indivíduos em contextos sociais específicos têm relação com a história e com a subjetividade. Benveniste (1991) se propôs a falar em enunciação, salientando a subjetividade na língua enquanto ação do produtor do enunciado. Ducrot revê a noção de combinatória semântica sugerindo que ela é explorada pelos sujeitos falantes para organização das relações intersubjetivas no diálogo (Paveau; Sarfati, 2006). A análise do discurso enfatiza o caráter linguístico do ato de argumentar, inserindo a argumentatividade no interior do próprio sistema da língua (Fávero; Koch, 1998). Dito de outro modo, passa-se da noção de estrutura focada na língua, para a ideia de estruturação que considera, também, a fala.

\section{A noção de estrutura do sistema e do registro de informação na documentação}

Saussure sublinhou, em seu Cours de Linguistique Géneral, suas ideias sobre o valor relacional dos elementos linguísticos, derivando daí uma série de dicotomias. Considerando que nenhum elemento da língua pode ser considerado isoladamente, postulou que a sincronia se estabelece como relação entre coisas existentes, de onde surge a noção de sistema, que posteriormente foi denominado estrutura (Lopes, 1987). Para ele, a língua é um sistema de valores, onde cada elemento se define em relação com outros elementos (Lopes, 1987, p.79).

Um fonema, um morfema, é definido nas suas relações com outros elementos do mesmo sistema e pela sua função no interior desses sistemas - primeira noção de forma -, e nunca a partir de suas propriedades, por exemplo, de sua estrutura acústica primeira noção de substância.

Eis que a língua constitui, no parecer de Saussure, uma forma e não uma substância: a língua não é um sistema de conteúdos (não existe um 'nível' semântico), mas um sistema de formas e de regras (valores). O conteúdo de um termo só é fixado, por isso, através da totalidade de que esse termo é parte, e a sua definição positiva deriva de uma definição relacional (ou definição negativa); o valor de um termo consiste nisso: um elemento é (definição positiva) tudo aquilo que os demais elementos do seu sistema não são (definição negativa) (Lopes, 1987).

Hielmslev (citado por Lopes, 1987, p.94) desenvolveu essa proposta afirmando que o Plano de Expressão (PE) das línguas naturais corresponderia ao sistema de significantes, e o Plano do Conteúdo (PC), ao sistema dos significados: a língua é uma forma específica organizada entre duas substâncias: a do conteúdo e a da expressão. A dicotomia forma/ substância no signo linguístico pode ser apresentada como segue (Quadro 1):

Vários autores da Documentação se referem explícita ou implicitamente à proposta de Hjelmslev (Lopes, 1987).

O conceito de documento em Documentação é apresentado como suporte material (continente) que serve de amparo ao conhecimento (conteúdo 
Quadro 1. O signo linguístico. específicas. Por isso, quando ocorre a análise do continente, realiza-se sobre o documento um tipo de análise da forma documental, e quando a operação realiza-se sobre o conteúdo, dá-se a análise da mensagem documentária (Garrido Arilla, 1996).

Para Garrido Arilla (1996), os conceitos de forma e conteúdo de um documento levaram a uma fronteira que força os pesquisadores a enquadrar as operações de um lado ou de outro, ou seja, operações da Análise Formal ou da Análise de Conteúdo do documento. Segundo ela, alguns autores afirmam que a Análise Documentária é um conjunto de operações efetuadas tanto no "continente quanto no conteúdo do documento", por meio das quais é extraída do documento primário certa informação, que transforma os documentos originais em secundários, identificativos dos primeiros.

García Gutiérrez (1984, p.65) opera com a dicotomia do signo linguístico saussureano para mostrar a estrutura e elementos do documento científico como meio comunicativo, por meio do seguinte esquema:

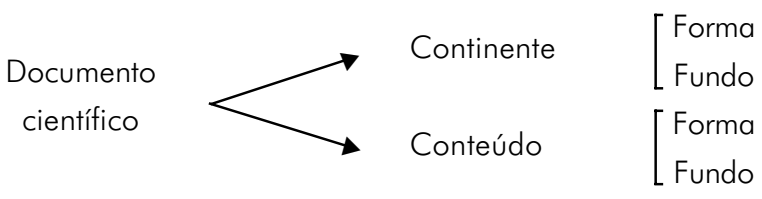

Segundo ele, o continente do trabalho científico compõe-se de duas partes:

- a forma (suporte material, papel, formato etc.); e

- o fundo (elementos de identificação do documento, como autor, editora, ano etc.).

O conteúdo do trabalho científico se divide, por sua vez, segundo os seguintes aspectos:

- forma do conteúdo (exposição, estrutura, apresentação dos dados etc.); e

- fundo do conteúdo ou conceitos utilizados (contribuições do trabalho, experiências, conclusões etc.).

Assim, o tratamento da forma e do fundo do continente refere-se à descrição física e dos elementos de identificação do documento, e o tratamento da forma e do fundo do conteúdo do documento refere-se à atribuição de seus assuntos (fundo), processo que faz uso da estrutura de apresentação dos conteúdos do documento (forma).

De modo semelhante, Moreiro González (2004) afirma que o dualismo proveniente das teorias de Saussure permite explicar a inseparável e interdependente associação relativa à composição dos documentos. Esses apresentam uma estrutura externa e uma estrutura abstrata. Moreiro González trata de Hjelmslev, o qual teria aberto a teoria do signo linguístico. Afirma que, a partir da função de interdependência entre o conteúdo e a expressão, Hielmslev distinguiv em cada um desses dois componentes os aspectos de forma e substância, estabelecendo quatro estratos com dois pares correlacionados: substância de conteúdo e forma de conteúdo; e substância da expressão e forma da expressão, como dissemos anteriormente.

Com base nas distinções estruturais apresentadas, Moreiro González (2004, p.24) discorre sobre os níveis de descrição, como segue.

Quanto à descrição da estrutura superficial, uma primeira derivação surge quanto à matéria de que é feito o documento, determinando o modo de ser tratado e armazenado, de acordo com os diferentes suportes físicos. A descrição da estrutura superficial, descrição externa ou catalogação busca a identificação do documento-objeto de informação, dando-se assim a primeira operação fundamental para transferir a carga informativa dos textos. A catalogação confirma a

TransInformação, Campinas, 22(1):7-17, jan./abr., 2010 
existência de um documento e concede a ele seus traços diferenciais de identificação física como objeto integrado a uma coleção. Os atributos dos documentos são reconhecidos por meio da coleta dos dados de sua estrutura formal. Constitui-se assim o tratamento físico, a partir de sua consignação a um determinado modelo, de acordo com as diferentes formas materiais em que está confeccionado ou disposto cada tipo de documento.

A análise da estrutura informativa profunda atende, por sua vez, à tipologia textual no que respeita à superestrutura do texto original, e à indexação e elaboração de resumos ${ }^{6}$ no que se refere ao conteúdo das macroestruturas.

O Quadro 2 proposto por Moreiro González (2004, p. 25) esquematiza suas ideias:

Observa-se que a ideia de que a catalogação se ocupa da descrição física do documento, em oposição à indexação que se atém aos seus conteúdos temáticos, faz parte da Documentação, provavelmente como decorrência da ênfase sobre a representação dos conteúdos temáticos dos documentos que marcou essa corrente. No contexto dos tradicionais estudos de Catalogação, a atividade é definida quanto ao objetivo de permitir a identificação de um documento, por meio da elaboração de registro que informe sobre sua existência de modo singular e inequívoco. Essa atividade inclui a descrição das características físicas do documento, mas não se esgota nela, como os próprios esquemas propostos por García Gutiérrez (1984) e Moreiro González (2004) demonstram.

Embora não tenha origem na Espanha, a Documentação desenvolveu abordagem própria nesse país, do que decorre que seus pesquisadores apresentem de modo recorrente referências teóricas comuns. Podemos dizer que as obras que têm subsidiado os autores espanhóis, por várias gerações, são essencialmente aquelas publicadas por Paul Otlet, embora nem sempre seja citado (Ortega, 2009b).

Desse modo, retoma-se os conceitos tratados por Otlet (1934) no início do século XX. Segundo Otlet o livro pode ser abordado como um continente - uma certa forma de livro e uma certa língua na qual se expressam as ideias - e como conteúdo - ideias que se referem a um certo assunto, consideradas em um certo lugar e em um certo tempo. Essas formas de abordar o livro seriam de duas classes: a forma da expressão objetiva, didática, científica, suscetível de progresso constante, como os moldes preparados para receber o pensamento; e as formas literárias propriamente ditas que correspondem aos gêneros e espécies estudadas pela retórica. Os elementos que constituem o livro elementos materiais, gráficos, linguísticos e intelectuais - são relativos ao continente ou forma no sentido amplo da palavra. Os elementos de conteúdo ou fundo são os científicos ou literários. Por trás do livro continente estaria o conteúdo, a literatura em sentido amplo.

Otlet dividiu todo o capítulo 2 - O livro e o documento - do Tratado de Documentação, a partir do que chamou de continente e de conteúdo, embora não de modo tão claro e didático como gostaríamos, além de explorar a noção de estrutura. Valeria investigar as referências em que Otlet se baseou para uso da noção de estrutura, ainda que se possa identificar nos anos 1930, quando o Tratado foi publicado, grande presença dessa noção nas correntes de pensamento vigentes ${ }^{7}$.

Quadro 2. Níveis da descrição documentária.

\begin{tabular}{|c|c|c|c|c|}
\hline \multirow{3}{*}{$\begin{array}{c}\text { Documentos } \\
\text { originais }\end{array}$} & Níve & descrição & Níveis da análise & \multirow{3}{*}{$\begin{array}{c}\text { Representações } \\
\text { referenciais }\end{array}$} \\
\hline & $\begin{array}{l}\text { Estrutura } \\
\text { superficial }\end{array}$ & $\begin{array}{c}\text { Suporte } \\
\text { Identificação do } \\
\text { documento-objeto }\end{array}$ & Catalogação & \\
\hline & $\begin{array}{l}\text { Estrutura } \\
\text { semântica }\end{array}$ & $\begin{array}{l}\text { Superestrutura } \\
\text { Macroestruturas }\end{array}$ & $\begin{array}{l}\text { Tipologia textual } \\
\text { Indexação } \\
\text { Elaboração de resumos }\end{array}$ & \\
\hline
\end{tabular}

Fonte: Moreiro González (2004, p.25).

- Alteramos a expressão indexação e resumo usada pelo autor para indexação e elaboração de resumos, pois trata-se de processos documentários, e não de produtos.

7 Segundo o Dicionário do Pensamento Social do século XX, Piaget, Kolakowski e Schaff observaram, durante os anos 1960 e 1970 , que o conceito de estrutura foi um elemento de importância maior na perspectiva filosófica e científica geral nos anos 1930 , refletindo-se em campos como a matemática, a biologia, a linguística e a psicologia da Gestalt (Bottomore, 1996, p.275). 


\section{A ESTRUTURA DO SISTEMA E DO REGISTRO DE INFORMAÇÃO E SEUS PROCESSOS DE CONSTRUÇÃO}

Green (2008) trata das relações como o coração da organização do conhecimento, segundo expressão que adota. Para ela, todo princípio de organização é constituído de uma ou mais relações, de tal forma que, sem relações não pode haver organização. As relações são usadas para navegar entre assuntos, assim como para localizar documentos os quais, juntos, dizem mais que a soma de suas partes.

Relações entre os elementos, no caso do sistema documentário, dão-se por meio dos pontos de acesso comuns entre os registros. Por isso, Panizzi fala, segundo interpretação de Tillet (1989) citada por Ríos Hilario (2003, p.45), em uma estrutura conceitual do catálogo que consiste em registros compostos de elementos de dados e de conexões entre registros. Os registros conectados formam agrupamentos que compartilham um tipo particular de relação.

A noção de estrutura é explicada pelas relações entre seus elementos. Ela implica articulação, internamente e no âmbito do sistema, a qual permite a identificação de características comuns entre os elementos que a compõem. $O$ registro de informação é, portanto, uma estrutura, pois é composto por forma (campos) e conteúdo (preenchimento dos campos) que devem estar articulados. Desse modo, a noção de estrutura, e não de justaposição, é que explica o registro, e facilita sua visualização e operação pelo documentalista e pelo usuário.

Essa noção está subjacente às operações de construção e gestão de sistemas documentários. Visando concretizar tal percepção, é proposta a seguinte sistematização para essas operações:

- determinação da estrutura de campos e de suas características, segundo tipologias documentais específicas e questões (previstas) de usuários;

- estabelecimento dos critérios para preenchimento dos campos e para escolha e forma dos pontos de acesso que comporão o índice de busca:

- elaboração da forma de apresentação da referência e do documento referenciado, quando for o caso;
- descrição formal e de conteúdo, ou seja, preenchimento dos campos e elaboração dos pontos de acesso; e

- adoção de rotinas de revisão de índices e de registros que garantam a consistência do sistema, ou seja, a coerência entre as descrições.

As etapas assim apresentadas demonstram que a Representação Descritiva e a Representação Temática não se definem de modo estanque, respectivamente, pelos processos de descrição formal e de conteúdo; há etapas que antecedem a descrição e são necessárias à sua interpretação e realização.

Os registros de informação dos sistemas documentários devem configurar-se como estruturas coerentes entre si, construídas a partir de formas que determinam e são determinadas pelos conteúdos. Trata-se, para qualquer registro de informação, de unidades estruturais que se quer ver presentes e operacionalizáveis no sistema. Para realizar a representação documentária (descritiva e temática), fazse necessário conceber a estrutura conceitual do registro, a qual exige conhecimento das características gerais dos campos, seus possíveis conteúdos e a inter-relação entre eles. A concepção estrutural do registro é realizada a partir dos elementos comuns que caracterizam cada tipologia documental e das questões (previstas) do usuário. Ou seja, as atividades de representação descritiva e de representação temática necessitam da definição prévia dos campos para responderem pelos seus conteúdos.

Desse modo, a questão que apontamos é a da implicação da anterioridade da identificação das formas e dos conteúdos que constituirão propriamente o registro.

Verifica-se, no entanto, que alguns formatos de registro bibliográfico, enquanto modelos de referência para a construção de registros de informação, embora observem características comuns entre elementos, não os articula convenientemente para que, de fato, se tenha uma configuração estrutural. Isso explica, ao menos em parte, muitas das dificuldades que 0 aluno e o profissional enfrentam diante das atividades práticas de representação documentária.

Daí decorre a necessidade prévia de compreensão lógica de sua organização estrutural, ou seja, articulando-se convenientemente os elementos que 
configuram o conjunto dos elementos de Representação Descritiva, bem como os de Representação Temática, como também esses dois níveis de representação entre si. A organização estrutural deve responder inteiramente pelo registro.

\section{CONSIDERAÇÕES FINAIS}

Representação Descritiva e Representação Temática constituem as bases para a elaboração de modelos de registros de informação no contexto da construção e gestão de sistemas documentários. Contudo os processos para a concepção estrutural dos registros e dos sistemas são pouco contemplados na literatura e no ensino de modo global e articulado, gerando baixa capacidade de generalização. Por tais motivos, é preciso considerar esse ponto ao definir e caracterizar a Organização da Informação, seja em termos da elaboração epistemológica realizada no âmbito das pesquisas acadêmicas, seja na concepção e atualização de projetos pedagógicos ou na efetivação de práticas profissionais documentárias.

Não à toa, as ontologias, taxonomias e topic maps produzem o registro completo. Embora inicialmente tenham sido comparados às linguagens documentárias, podem ser considerados bases de dados que se iniciam por uma estrutura prévia que, aplicada, transforma dados em documentos estruturados, a exemplo da produção dos documentos eletrônicos. Apenas a partir da sistematização do conhecimento de processos e instrumentos documentários, transformando-o em aporte teórico e metodológico consistente, será possível realizar contribuições para a reflexão sobre instrumentos de representação da informação ou similares produzidos no contexto de outras áreas, ou fazer seu uso em nosso benefício.

Como dissemos, a rede de relações que compõe uma estrutura não é aparente, mas supõe princípio epistemológico anterior, que é o da sistematicidade do real. Na Documentação, a ideia de arranjo ou estrutura é utilizada para tornar explícita uma hipótese de sistematização do real a partir de um modelo. No domínio da linguagem documentária, recorre-se à escolha de termos considerados representativos de um universo do saber ou de uma área de atividade e, em seguida, à identificação das relações entre eles, segundo uma definiçãa de partida. No domínio dos registros de informação e dos sistemas documentários, o mesmo princípio pode ser o arcabouço que dá forma a um conjunto de campos que são preenchidos segundo suas características (campo de autoria, campo de título etc).

No que toca ao conteúdo dos documentos, a noção de arranjo ou estrutura permitiu alterar o quadro empírico de construção das linguagens documentárias. Esse não é o caso dos formatos de registro bibliográfico que, muitas vezes, constituem um conjunto antes como resultado da soma de campos do que de sua articulação. Assim, propor maior grau de estruturação aos formatos pode fazer a diferença na capacidade dos sistemas de responder às demandas por informação dos usuários, bem como orientar o trabalho dos documentalistas.

Como apenas o sistemático é inteligível cientificamente, a noção de estrutura mostra-se potencialmente rica para fundamentar a ideia de registro de informação para além dos princípios subjacentes às normas de descrição, as quais são posteriores à concepção estrutural do registro. Desse modo, concluí-se que tal noção é vital para uma proposta mais consistente de princípios e métodos para a construção e gestão de sistemas documentários.

Uma vez que a noção de estrutura confere referência pedagógica ao fazer documentário tanto de documentalistas quanto de usuários, a continuidade desta pesquisa poderia enfatizar estudos que, partindo dela, tratam da noção de estruturação como meio de fornecer maior dinamicidade do sistema e, consequentemente, maior interatividade dos usuários com os sistemas documentários. Isso implicaria a possibilidade de conceber tantos campos para o registro quantos fossem os aspectos passíveis de interesse para a representação no sistema. Não se trata simplesmente de incluir um maior número de campos, mas de assegurar que eles, ou parte deles, possam articular-se de modo mais dinâmico para representar um maior espectro de facetas ou para oferecer diferentes níveis de organização. De qualquer modo, é preciso lembrar que a organização dos registros de informação dos sistemas documentários não tem um fim em si mesma. Eles são constituídos para permitir a busca e a recuperação. A diferença entre utilizar a noção de estrutura que, ao invés de fechar sobre si mesma, permita uma participação pró-ativa do usuário, é sedutora. Mas essa é outra pesquisa. 


\section{REFERÊNCIAS}

ABADAL, E.; CODINA, L. Bases de datos documentales: características, funciones y método. Madrid: Síntesis, 2005. (Biblioteconomía y Documentación).

BENVENISTE, É. Problemas de lingüística geral, I. Campinas: Pontes, 1991.

BOTTOMORE, T. Estruturalismo. In: OUTHWAITE, W.; BOTTOMORE, T. (Ed.). Dicionário do pensamento social do século XX. Rio de Janeiro: Jorge Zahar, 1996.

COHEN, D.M. O consumidor da informação documentária: o usuário de sistemas documentários visto sob a lente da análise documentária. 1995. Dissertação (mestrado) - Escola de Comunicações e Artes, Universidade de São Paulo, São Paulo, 1995.

FÁVERO, L.L.; KOCH, I.G.V. Lingüística textual: introdução. 4.ed. São Paulo: Cortez, 1998.

FERRATER MORA, J. Dicionário de filosofia. São Paulo: Martins Fontes, 1998.

GARCÍA GUTÍERREZ, A.L. Lingüística documental: aplicación a la documentación de la comunicación social. Barcelona: Mitre, 1984.

GARRIDO ARILLA, M.R. Teoría e historia de la catalogación de documentos. Madrid: Síntesis, 1996.

GREEN, R. Relationships in knowledge organization. Knowledge Organization, v. 35, n. 2/3, p. 150-9, 2008.

LARA, M.L.G. Representação documentária: em jogo a significação. 1993. Dissertação (mestrado) - Escola de Comunicações e Artes, Universidade de São Paulo, São Paulo, 1993.

LOPES, E. Fundamentos da lingüística contemporânea. São Paulo: Cultrix, 1987.
MEYRIAT, J. Document, documentation, documentologie. Schéma et Schématisation, n. 14, p.51-63, 1981.

MOREIRO GONZÁLEZ, J.A. El contenido de los documentos textuales: su análisis y representación mediante el lenguaje natural. Gijón: Trea, 2004. (Biblioteconomía y Administración Cultural, 97).

MOREIRO GONZÁLEZ, J.A. Introducción al estudio de la información y la documentación. Medellín: Editorial Universidad de Antioquia, 1998. (Colección Medios y Mensajes).

ORTEGA, C.D. Os registros de informação dos sistemas documentários: uma discussão no âmbito da representação descritiva. 2009a. Tese (doutorado em Ciência da Informação) Escola de Comunicações e Artes, Universidade de São Paulo, São Paulo, 2009.

ORTEGA, C.D. A Documentação como uma das origens da Ciência da Informação e base fértil para sua fundamentação. Brazilian Journal of Information Science, v. 3, n. 1, p.3-35, 2009b. Disponível em: <http://www2.marilia.unesp.br/revistas/ index.php/bjis > . Acesso em: 26 jun. 2010.

OTLET, P. El tratado de documentación: el libro sobre el libro: teoría y práctica. Bruxelles: Mundaneum, 1934.

PAVEAU, M.A.; SARFATI, G.-É. As grandes teorias da lingüística: da gramática comparada à pragmática. São Carlos: Claraluz, 2006.

PEÑALVER SIMÓ, M. La lingüistica estructural y las ciencias del hombre. Buenos Aires: Nueva Visión, 1972.

RÍOS HILARIO, A.B. Nuevos horizontes en el análisis de los registros y la normativa bibliográfica. Gijón: Trea, 2003.

SAUSSURE, F. Curso de lingüística geral. São Paulo: Cultrix; 1969.

TÁLAMO, M.F.G.M. Linguagem documentária. São Paulo: APB, 1997. (Ensaios APB, 45). 
